\title{
Basking and diurnal foraging in the dasyurid marsupial Pseudantechinus macdonnellensis
}

\author{
Chris R. Pavey $^{\mathrm{A}, \mathrm{B}}$ and Fritz Geiser ${ }^{\mathrm{A}}$ \\ ${ }^{A}$ Centre for Behavioural and Physiological Ecology, Zoology, University of New England, \\ Armidale, NSW 2351, Australia. \\ ${ }^{\mathrm{B} C}$ Corresponding author. Present address: Biodiversity Conservation, Department of Natural Resources, \\ Environment, and the Arts, Alice Springs, PO Box 1120, Alice Springs, NT 0871, Australia. \\ Email: chris.pavey@nt.gov.au
}

\begin{abstract}
Several mammal species bask to passively rewarm during arousal from torpor, a strategy that can decrease energetic costs. Nothing is known about basking behaviour in these species or the trade-offs between energetic benefits of basking and potential costs associated with changes in activity patterns and increased predation risk. We assessed basking during winter in Pseudantechinus macdonnellensis, an Australian arid-zone marsupial that belongs to a family (Dasyuridae) that is typically nocturnal. Animals were implanted with temperature-sensitive transmitters to assess body temperatures and to assist in visually locating animals active during the day. Tagged animals regularly exhibited diurnal foraging. Foraging bouts occurred throughout the day; however, most bouts were observed within $3 \mathrm{~h}$ of sunset. By comparison, basking occurred much more frequently in the morning. Basking and a shift towards diurnal foraging in winter is associated with a decrease in richness and abundance of predators. $P$. macdonnellensis appears to compensate for the occurrence of torpor during the active phase (i.e. night) in winter by changing activity patterns such that foraging commences during what is usually the rest phase. These activity patterns are not expected to occur during the remainder of the year.
\end{abstract}

\section{Introduction}

In order to survive, animals need to balance energetic requirements with the need to avoid predation (Lima and Dill 1990; Lima and Bednekoff 1999). This trade-off may be particularly challenging for those endothermic mammals that bask to passively rewarm during arousal from torpor when their body temperature $\left(\mathrm{T}_{\mathrm{b}}\right)$ and coordination are reduced. Nevertheless, recent studies have documented this previously unknown behaviour in several small (body mass $<100 \mathrm{~g}$ ) marsupial and placental mammals (Geiser et al. 2002, 2008; Mzilikazi et al. 2002). A specific challenge faced by nocturnal endothermic mammals that passively rewarm by basking is that these species undergo torpor during the latter half of the night, during what is normally their active phase, and subsequently rewarm by basking in sun-exposed microhabitats in the morning, during their normal rest phase. Passive rewarming by basking is an energetically advantageous strategy and has been estimated to reduce the cost of rewarming by up to $85 \%$ in marsupial mammals and can increase rewarming rates (Geiser et al. 2004, 2008).

Nocturnal torpor and early morning basking by nocturnal endotherms involves a trade-off between the energy savings of passive rewarming and potential costs of increased predation risk during diurnal exposure and reduced foraging time from disruption to nocturnal activity rhythms. However, passive rewarming by basking also provides the opportunity for animals to shift activity periods across seasons. Specifically, during the torpor season the cost of reduced nocturnal foraging activity can be overcome if animals can forage during the day. Diurnal foraging during winter may be energetically advantageous, especially for insectivores, because of greater prey availability during the day. Foraging during the later period of the day and for several hours after sunset, before the period after midnight when ambient temperatures $\left(\mathrm{T}_{\mathrm{a}} \mathrm{s}\right)$ are the lowest of the 24-h daily cycle, is likely to be an energetically advantageous strategy during the torpor season. However, diurnal foraging could also involve an increased predation risk.

The fat-tailed false antechinus, Pseudantechinus macdonnellensis, a small marsupial (18-33 g body mass) is an example of a species that undergoes nocturnal torpor and passively rewarms by basking after sunrise. Therefore, it is a species that may potentially shift activity patterns during the torpor season. The species is restricted to rocky outcrops and ranges in arid and semiarid Australia where it feeds on a diversity of insects and spiders, and occasionally captures other invertebrates and rodents (Gilfillan 2001a; Burwell et al. 2005). During winter $P$. macdonnellensis is active for several hours during the first half of the night, typically enters torpor after midnight and undergoes passive rewarming by basking on sunexposed rocks soon after sunrise in the morning (Geiser et al. 2002; Geiser and Pavey 2007). Annual variation in activity pattern and torpor use of $P$. macdonnellensis has not been assessed; however, the results of mark-recapture studies indicate that the study population is nocturnal during the remainder of 
the year (Gilfillan 1995, 2001b; C. Pavey, unpubl. data). Therefore, we expect that the activity pattern described above occurs only in winter (May-August) when nocturnal $\mathrm{T}_{\mathrm{a}} \mathrm{s}$ fall close to $0^{\circ} \mathrm{C}$ and diurnal $\mathrm{T}_{\mathrm{a}} \mathrm{s}$ are mild (Geiser and Pavey 2007).

Here we address the use of diurnal activity in P. macdonnellensis by examining the behaviour and activity rhythms of a population for which we have already characterised the thermal environment, and assessed torpor use, spatial ecology and diet (Geiser et al. 2002; Pavey et al. 2003; Burwell et al. 2005; Geiser and Pavey 2007). The behavioural and activity data described here were collected at the same time as the study of thermal biology. We first determined the extent of diurnal foraging in the study population and assessed whether early morning basking was associated with diurnal activity, i.e. whether animals that passively rewarmed in the morning subsequently foraged during the day. Next, we examined whether passive rewarming by basking and diurnal foraging in the study population is correlated with a decrease in the risk of predation during winter. We did this by assessing the predator species present in the study area and determining the seasonal and daily activity patterns of each species. This enabled us to correlate predator activity with the presence of basking $P$. macdonnellensis at the site. We also assessed mechanisms by which basking animals may reduce predator pressure and maximise passive rewarming. Specifically, we examined behaviour of basking animals and the characteristics of basking sites, including location relative to torpor sites.

\section{Methods}

\section{Study area and animals}

Behavioural observations were carried out over the austral winter (between 14 June and 11 July 2001$)$ at Ormiston Gorge $\left(23^{\circ} 37^{\prime} \mathrm{S}\right.$, $132^{\circ} 45^{\prime} \mathrm{E}$ ), West MacDonnell National Park, Northern Territory. This period is likely to be during the mating season for the study population (Gilfillan 2001a). Weather during the study period was conducive to observing basking, being sunny with the exception of a single day that was overcast early in the morning and then intermittently for much of the day.

The study population of $P$. macdonnellensis occurs in an area of hummock grassland (dominated by Triodia brizoides) with a sparse overstorey of acacia (Acacia spondylophylla) growing on rocky hills. The area is characterised by low, unpredictable rainfall and extreme $\mathrm{T}_{\mathrm{a}}$ that ranges from -6 to $41^{\circ} \mathrm{C}$ on an annual basis. During the study $\mathrm{T}_{\mathrm{a}}$ (measured to the nearest $0.5^{\circ} \mathrm{C}$ using data loggers: Thermochron, iButton, Dallas Semiconductor; placed $1 \mathrm{~m}$ above the ground in the shade) ranged between a minimum of $2.0^{\circ} \mathrm{C}$ and a maximum of $24.0^{\circ} \mathrm{C}$ with a mean of $12.6 \pm 5.8^{\circ} \mathrm{C}$ (Geiser and Pavey 2007). Data loggers were wrapped in a sheet of white paper to minimise uptake of radiant heat.

We captured our study animals in aluminium box traps (Elliot type A, Elliott Scientific Ltd, Upwey, Melbourne, Vic.) baited with a mixture of peanut butter and rolled oats and containing a layer of polyester fibre for insulation. Traps were set along sandstone gullies and cliffs usually beneath rock ledges that provided protection from inclement weather and predators. Traps were set in the evening and checked at sunrise in the morning. Animals were placed in cloth bags and transferred to the field laboratory situated $\sim 500 \mathrm{~m}$ from the trap site. Six animals were implanted intraperitoneally with calibrated temperature-sensitive transmitters (FM single-stage, mass 2 g, Sirtrack Ltd, Havelock North, New Zealand) under oxygen/isoflurane anaesthesia in a field laboratory (see Geiser and Pavey 2007 for further details of the methodology). Transmitter mass was, on average, $6.5 \%$ of an animal's body mass. Our observations of apparently normal behaviour including successful foraging by the tagged animals, and use of large home ranges that were greater in size than in a previous study indicate that transmitter mass did not impair movement (Pavey et al. 2003).

Animals were given $>24 \mathrm{~h}$ to recover from surgery, during which time they were placed individually in holding cages with food (commercial dog food) and water supplied ad libitum. We monitored the recovery from surgery regularly. Animals were released at the capture site in the late afternoon within two days of surgery. All animals recovered from surgery and remained in the study area for at least 19 days after release. Post-surgery behaviour appeared normal. Capture and care procedures were carried out under permit from the Animal Ethics Committee of the University of New England, Armidale, Australia (authority no. AEC01/029).

\section{Assessment of predators}

We assessed the predator species present within the area occupied by the study population of $P$. macdonnellensis using both field surveys (carried out between 2001 and 2006) and expert knowledge. Field survey methods included: (1) daytime walking transects for active or resting reptiles, mammals and birds of prey; (2) active searches for reptiles under rocks, logs and leaf litter; (3) spotlight transects for nocturnal reptiles, birds and mammals; (4) vehicle-based road transects (day and night) for reptiles, birds and mammals; (5) use of box traps (Elliot type A) to capture reptiles; and (6) identification of road-killed specimens.

Collectively, these methods allowed us to generate a comprehensive list of predatory species. We defined a species as a 'potential predator' of $P$. macdonnellensis if it was known to capture terrestrial small mammals of similar size and foraged within the sandstone slopes and plateaus to which P. macdonnellensis is restricted. We used previous research on home-range size from a range of sources as an indication of the relative number of individuals of each predator species likely to reside within our study area of 625 ha (Table 1). To do this we made the assumption that suitable habitat was uniformly available across the site for each species and, therefore, that home-range size was a useful surrogate of abundance. To determine seasonality of activity we divided the year into 'winter' (MayAugust) and the 'rest of the year' on the basis of $\mathrm{T}_{\mathrm{a}}$ and assessed when each species was active and whether it was nocturnal or diurnal or both. These assessments were based on seasonality in the study area. A species was considered to be inactive in winter if most individuals in the population were inactive for most of the winter (not necessarily $100 \%$ of the population).

\section{Behavioural observations}

Tracking the animals with manual receivers allowed us to obtain behavioural data during basking. On most days, search effort was intensified during two periods: within $3 \mathrm{~h}$ of sunrise (range of sunrise times during the study period was $0718-0722$ hours), and between early afternoon and $1 \mathrm{~h}$ after sunset (range of sunset times 
during the study period was 1800-1806 hours). We searched for signals from tagged animals by scanning the area near the last recorded location for each individual from an elevated vantage point. The rocky nature of the study area meant that such elevated positions were plentiful. If we did not receive a signal we walked across the study area and scanned for a signal every $50-100 \mathrm{~m}$. Once a signal was detected, we located the position of the animal by circling the general area from which the signal was received on foot (the 'homing-in' method of White and Garrott 1990). During the monitoring period we attempted to visually locate the animal. Manual readings of the pulse repetition rate of the transmitter signal provided a measure of the $\mathrm{T}_{\mathrm{b}}$ of the animal and, therefore, its likely activity as follows: $\mathrm{T}_{\mathrm{b}}$ of $19-29^{\circ} \mathrm{C}$, torpor or commencing rewarming, including potential basking; $\mathrm{T}_{\mathrm{b}} \geq 30^{\circ} \mathrm{C}$, normothermic resting or active. This method was used to rapidly ascertain $T_{b}$ in the field so that basking animals could be located. Accurate $T_{b}$ measurements involved the methodology detailed in Geiser and Pavey (2007). If an animal was potentially basking, the observer slowly approached the general location of the signal taking care not to disturb the target animal. We scanned the area using binoculars to find the animal.

Observers monitored and recorded the behaviour of target animals for as long as possible and recorded behaviour, proportion of the animal in the sun, orientation and activity. We classified the behaviour of animals into the categories described below.

Basking. This behaviour occurred when an individual was resting, usually on a rock surface, with some or all of its body exposed to direct sunlight (Fig. 1). During basking the animal was either: (1) stretched flat with its ventral surface resting on a rock surface; (2) standing on its hind limbs with the tail under the body and the head and anterior half of the body resting on a rock; or
(3) lying on its side with the head positioned under one of the forelimbs or curled up in a ball.

Foraging. The animal was actively searching for food among vegetation or in leaf litter. Prey capture and consumption are also included in this category.

Resting in the shade. Similar to basking except that no part of the animal was in contact with direct sunlight.

Refuge use. This behaviour was assumed to have occurred when animals moved from view into cracks and crevices among rocks.

Commuting. Direct and rapid movement from one location to another, for example, from a basking site to a refuge site.

\section{Relationship between passive rewarming and basking}

We were able to use radio-telemetry to both assess $T_{b}$ and to assist in visually locating active animals during the day so that we could observe basking and foraging behaviour. Thermal data were collected only when an animal was close enough to a receiver/ logger for its signal to be detected (see Geiser and Pavey 2007), so we cannot establish a link between basking and passive rewarming for all observations of basking. However, our thermal data, published separately (Geiser and Pavey 2007) demonstrate the frequent use of passive rewarming in the study population such that we assume that most instances of basking in the morning involved passive rewarming.

\section{Statistical analysis}

We used a Chi-square test of independence to compare the occurrence of basking and foraging in relation to time since sunrise. Our study design, which involved basking and foraging observations on six individuals, might have violated the

Table 1. Potential predators of $P$. macdonnellensis at Ormiston Gorge, Australia

Details of home-range size (as an indication of abundance) and activity patterns are provided. Activity: d, predominantly diurnal; n, predominantly crepuscular and/or nocturnal; sn, typically diurnal but some nocturnal activity during summer

\begin{tabular}{|c|c|c|c|c|c|}
\hline Class/Order & Family & Species & Activity rhythm & Home range (ha) & Source \\
\hline \multicolumn{6}{|l|}{ Reptilia } \\
\hline \multirow[t]{3}{*}{ Lacertilia } & \multirow[t]{3}{*}{ Varanidae } & Varanus giganteus & $\mathrm{d}$ & 12.3 & \multirow[t]{2}{*}{ King et al. (1989) } \\
\hline & & Varanus acanthurus & $\mathrm{d}$ & no data & \\
\hline & & Varanus tristis & $\mathrm{d}$ & Male: 40.4 ; female: 3.7 & Thompson et al. (1999) \\
\hline \multirow[t]{6}{*}{ Serpentes } & \multirow{2}{*}{ Boidae } & Antaresia stimsoni & $\mathrm{n}$ & no data & \multirow{5}{*}{ Shine and Fitzgerald $(1996)^{\mathrm{A}}$} \\
\hline & & Morethia spilota bredli & $\mathrm{n}$ & $22.5^{\mathrm{B}}$ & \\
\hline & \multirow{4}{*}{ Elapidae } & Acanthopsis pyrrhus & $\mathrm{n}$ & no data & \\
\hline & & Pseudechis australis & $\mathrm{d}, \mathrm{sn}$ & no data & \\
\hline & & Pseudonaja nuchalis & $\mathrm{d}, \mathrm{sn}$ & no data & \\
\hline & & Pseudonaja textilis & $\mathrm{d}$ & 5.8 & Whitaker and Shine (2003) \\
\hline \multicolumn{6}{|l|}{ Aves } \\
\hline \multirow{4}{*}{ Falconiformes } & \multirow{4}{*}{ Accipitridae } & Haliastur sphenurus & $\mathrm{d}$ & Pair: 1900 & Marchant and Higgins (1993) \\
\hline & & Accipiter fasciatus & $\mathrm{d}$ & Male: 266 ; female: 274 & Burton and Olsen $(2000)^{\mathrm{A}}$ \\
\hline & & Falco berigora & $\mathrm{d}$ & Pair: 1000 & Marchant and Higgins (1993) \\
\hline & & Falco cenchroides & $\mathrm{d}$ & Pair: 540 & Marchant and Higgins (1993) \\
\hline Caprimulgiformes & Podargidae & Podargus strigoides & $\mathrm{n}$ & Pair: $40-80$ & Higgins (1999) ${ }^{\mathrm{A}}$ \\
\hline \multirow[t]{2}{*}{ Strigiformes } & \multirow[t]{2}{*}{ Strigidae } & Ninox novaeseelandiae & $\mathrm{n}$ & Male: $37-100$ & Higgins $(1999)^{\mathrm{A}}$ \\
\hline & & Tyto alba & $\mathrm{n}$ & Pair: 500 & Higgins (1999) \\
\hline \multicolumn{6}{|l|}{ Mammalia } \\
\hline \multirow[t]{2}{*}{ Carnivora } & Canidae & Canis lupus dingo & $\mathrm{d}$ and $\mathrm{n}$ & 18210 & Eldridge et al. (2002) \\
\hline & Felidae & Felis catus & $\mathrm{d}$ and $\mathrm{n}$ & Male: 2210.5 & Edwards et al. (2001) \\
\hline
\end{tabular}

\footnotetext{
${ }^{\mathrm{A}}$ Study area outside arid/semiarid zone. $\quad{ }^{\mathrm{B}}$ Data from another subspecies.
} 
assumption of independence that needs to be met for Chi-square tests (Kramer and Schmidhammer 1992). However, the length of time over which data were collected ( 28 days) and the number of animals involved suggests that each bout we observed was likely to be independent of previous bouts. We consider the Chi-square test to be appropriate under these circumstances.

To assess the correlation between duration of basking bouts and time since sunrise we performed a Spearman rank correlation. Data were pooled across individuals to increase sample size. A one-sample $t$-test was used to compare mean minimum $\mathrm{T}_{\mathrm{b}}$ among animals with different proportions of torpor use. Means are presented \pm standard deviation (s.d.). The $\alpha$ value was $0.05 . N$ denotes the number of observations, whereas $n$ denotes the number of individuals/species.

\section{Results}

\section{Diurnal foraging}

Radio-tagged animals regularly foraged during the day. We observed 24 foraging bouts by four tagged animals (two male, two female) on 17 observation-days ( 1 observation-day = an animal observed foraging on one day) (Fig. 2). Foraging bouts occurred throughout the day; however, most bouts were observed within $3 \mathrm{~h}$ of sunset. All foraging bouts within $2 \mathrm{~h}$ of sunrise were those of one animal, Male 15 (Fig. 2). This male spent only $8.1 \%$ of the recorded time in torpor, in contrast to the $19.8-38.5 \%$ observed in the other individuals. Moreover, the mean minimum $\mathrm{T}_{\mathrm{b}}$ of this individual $\left(27.7^{\circ} \mathrm{C}\right)$ was higher than for the other individuals $\left(24.2 \pm 3.2^{\circ} \mathrm{C}, P<0.05\right.$, one-sample $t$-test). The other three individuals did not begin foraging until $260 \mathrm{~min}$ after sunrise. By comparison, the occurrence of basking, based on 44 bouts by five tagged (three male, two female) and an unmarked animal on 25 observation-days, was much greater in the morning: between $1 \mathrm{~h}$ after sunrise and midday (Fig. 2). Basking times ranged from 107 to $516 \mathrm{~min}$ after sunrise, with the latest bout within $125 \mathrm{~min}$ of sunset.

To assess variation in the timing of diurnal basking and foraging, daylight hours were divided into three categories, each of 3 h duration: $2-5,>5-8$, and $>8-11$ h after sunrise. All basking

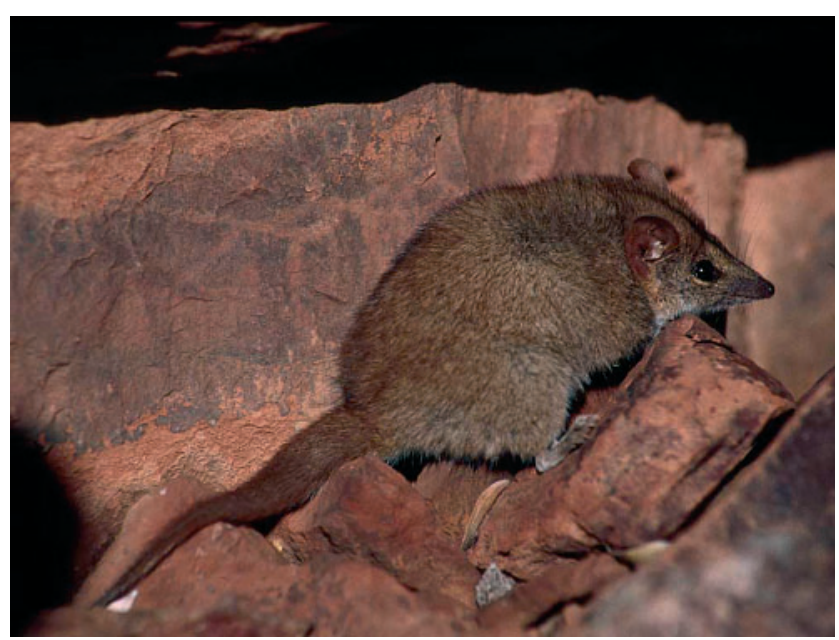

Fig. 1. Pseudantechinus macdonnellensis basking during passive rewarming on an exposed rock surface. and foraging observations took place between 1 and $10.5 \mathrm{~h}$ after sunrise. Male 15 was excluded from the analysis. Occurrence of the two activities varied significantly in relation to time since sunrise $\left(\chi^{2}=24.72\right.$, d.f. $\left.=2, P<0.001\right)$.

Three of the radio-tagged $P$. macdonnellensis were observed basking in the morning and foraging in the afternoon of the same day ( $N=8$ observation-days). On two occasions animals finished basking and began foraging soon after within a short distance of the basking site. However, this switching behaviour was observed only around midday or later. For example, on 6 July a female that was basking between 1015 and 1138 hours on an exposed rock surface, with a $\mathrm{T}_{\mathrm{b}}$ of $24.1^{\circ} \mathrm{C}$ when first seen, briefly retreated into an adjacent rock crevice and then re-emerged and began foraging in leaf litter within $0.5 \mathrm{~m}$ of the crevice. The animal captured prey, a beetle larva (Coleoptera), within $5 \mathrm{~min}$ and returned to the crevice to consume the prey. A male behaved in a similar manner on 15 June and moved at a $\mathrm{T}_{\mathrm{b}}$ of $31.9^{\circ} \mathrm{C}$. It completed a bout of basking at 1306 hours, moved into an adjacent refuge site and returned within $60 \mathrm{~s}$ to pursue a large fly (Diptera, Muscidae) within $0.5 \mathrm{~m}$ of the basking site.

\section{Predation risk}

Pseudantechinus macdonnellensis is within the prey size range of 18 species of vertebrates that are resident in the study area and are known to capture terrestrial mammals (Table 1). Potential predators include snakes $(n=6)$, varanid lizards $(n=3)$, aerialforaging birds $(n=7)$, and introduced carnivores $(n=2)$. Only one species, Varanus tristis, has been observed attempting to capture P. macdonnellensis (G. Fyfe, pers. comm.); no other species is known to be a definite predator.

The number of predator species active in winter (MayAugust) compared with the rest of the year was reduced by $50 \%$ for diurnal species and 55\% for nocturnal species (Fig. 3). The reason for the decline was the lack of activity of all species of snakes and lizards in winter (Fig. 3). The home-range estimates

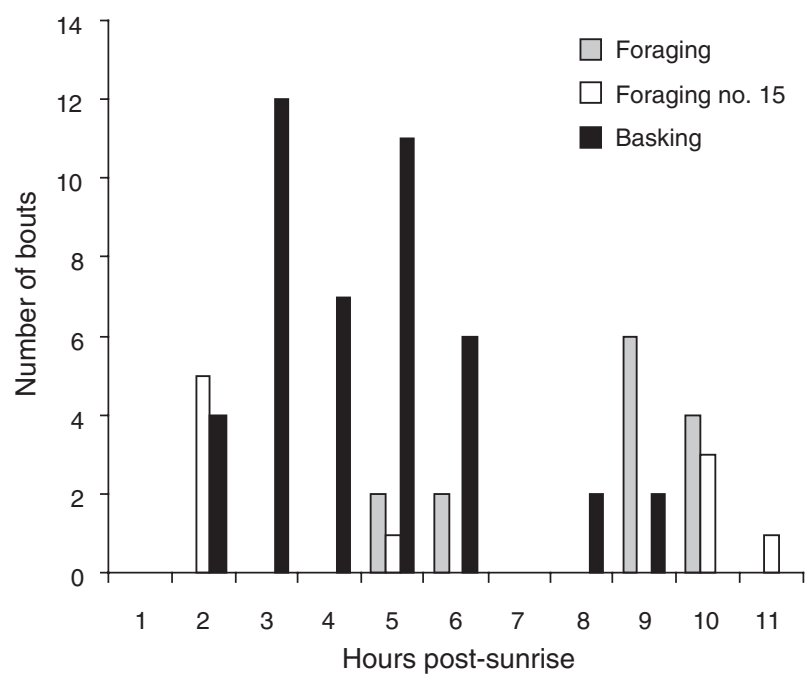

Fig. 2. Diurnal occurrence of basking and foraging observations of P. macdonnellensis. Foraging bouts of one individual (Male 15) are separated from those of the other animals. Sunset occurred between $10 \mathrm{~h} 40 \mathrm{~min}$ and $10 \mathrm{~h} 47 \mathrm{~min}$ after sunrise during the study period. 
(Table 1) show that snakes and lizards have a smaller home range than birds of prey and carnivores and, therefore, that reptiles will be the predatory group with the highest density on the study site.

\section{Characteristics of basking sites}

Twenty discrete basking sites were located during the study. Basking sites all occurred on sandstone, either along cliffs, exposed rock surfaces on hill slopes or beside gullies. Basking sites were mostly on exposed and bare rock surfaces adjacent to vertical rock walls $(n=12)$. Other basking sites were on bare rock surfaces beneath rocky overhangs $(n=2)$, bare rock surfaces in crevices and cracks below the ground surface $(n=3)$ and rock surfaces beneath grasses (either Eriachne or Triodia) and fallen vegetation $(n=3)$. Most sites were sun-exposed in the morning and we observed animals basking at each site. Basking sites were usually within $10 \mathrm{~m}$ and often within $1 \mathrm{~m}$ of torpor sites used the same morning. Several animals alternated between basking on exposed rock surfaces and spending time within adjacent refuge sites during the course of a morning.

\section{Basking behaviour}

Animals typically basked with the back oriented towards the sun (mean proportion basking time \pm s.d. $=0.79 \pm 0.14$ ) whereas the flanks faced the sun during $0.20 \pm 0.14$ of basking time $(n=5$, $261 \mathrm{~min}$ of observation). The percentage of the body of a basking animal in direct sunlight (mean proportion basking time \pm s.d.) was as follows: $100 \%, 0.60 \pm 0.40 ;>90 \%, 0.03 \pm 0.07 ; 50-90 \%$, $0.33 \pm 0.43$; and $<50 \%, 0.03 \pm 0.05(n=5,187$ min observation). The duration of completed basking bouts varied with time since sunrise. Bout length was longest soon after sunrise and decreased with increasing time since sunrise (Fig. 4). There was a significant negative correlation between duration of basking bouts and time since sunrise $\left(r_{s}=-0.44, P<0.05, n=21\right)$.

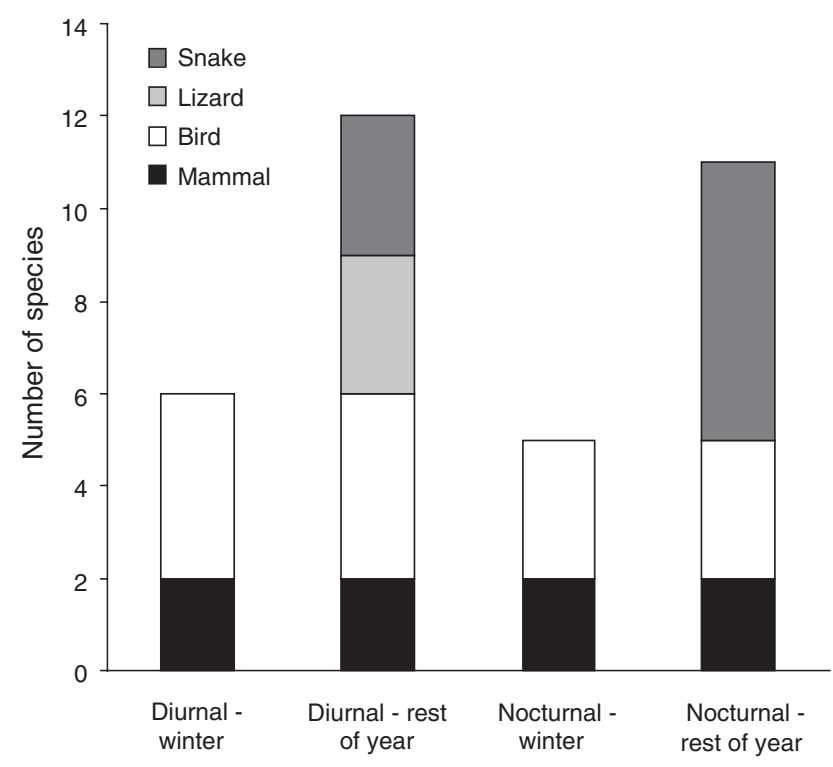

Fig. 3. The number of diurnal and nocturnal vertebrate species that are potential predators of small mammals active in the study area during winter (May-August) and the rest of the year.
Basking animals did not remain stationary for long periods and regularly changed body position or posture. These changes included altering orientation towards the sun by as much as $180^{\circ}$, and small movements of the body to increase or decrease the amount of sun-exposure. We also observed short-duration $(<5 \mathrm{~s})$ activities such as ear scratching and grooming the fur in several basking animals. Basking animals adjusted their body posture or position, on average, every $4.99 \min (n=5, N=43$ changes).

\section{Discussion}

Our findings show that the study population of P. macdonnellensis modified activity patterns in winter by entering torpor during the active phase, and basking and foraging during what is normally the rest phase. Radio-tagged animals actively foraged from midday onwards during daylight (Fig. 2) and continued to forage during the early part of the night, with torpor commencing around or soon after midnight (Geiser and Pavey 2007). Although entry into torpor during the active phase occurs in several placental mammals that passively rewarm during arousal (Schmid 2000; Mzilikazi and Lovegrove 2005) and seasonal shifts in activity periods within the active phase occur in other mammals (Kenagy et al. 2002), seasonal switching of the active phase as shown by $P$. macdonnellensis appears to be rare among mammals. The strategy employed by P. macdonnellensis should maximise energetic savings because animals are inactive during the period of lowest $\mathrm{T}_{\mathrm{a}}$.

Our observations of diurnal activity in winter by P. macdonnellensis coincide with a decrease in the diversity of predators active within the habitat of the study population compared with the rest of the year (Fig. 3). Significantly, the predators that are inactive in winter - terrestrial lizards (Varanidae) and snakes - are the predator group against which basking $P$. macdonnellensis have no obvious defences. Basking P. macdonnellensis selected sites that were protected overhead and located close to refuge sites. All 20 basking sites afforded a high level of protection, with eight sites either protected by a rocky overhang or located in cracks and crevices below the surface or beneath vegetation, and the remainder positioned

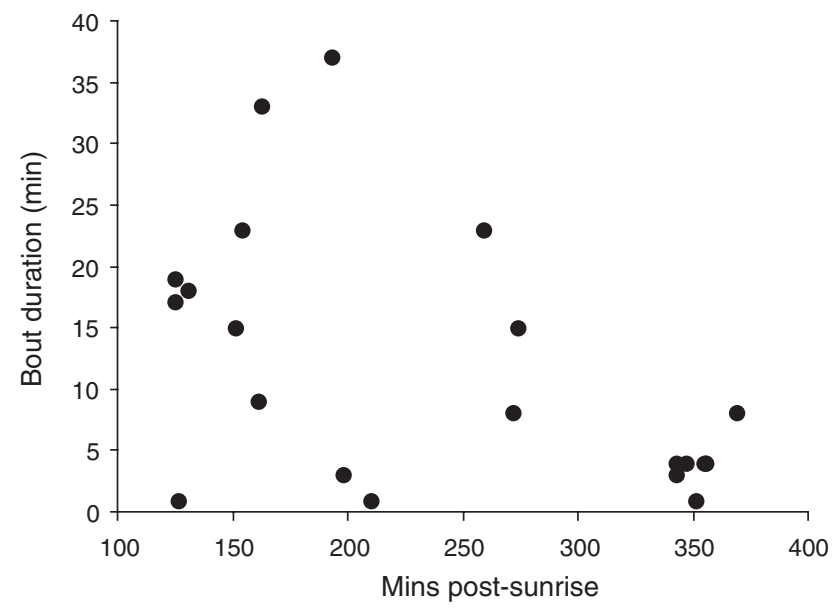

Fig. 4. Variation in duration of basking bouts of P. macdonnellensis with time after sunrise. 
adjacent to a vertical rock surface such as a cliff face or rock slab. Such basking locations reduce the likelihood of animals being located and captured by aerial-foraging diurnal birds or cursorial mammals, the two predator groups that are active in winter. However, reptilian predators can pursue $P$. macdonnellensis into refuge sites and are likely to represent a greater threat. The threat posed by varanid lizards and diurnal elapid snakes is likely to be high because these predators actively seek prey in contrast to 'sit and wait' foragers such as pythons and Acanthopsis pyrrhus (Bedford and Christian 1998).

In terms of relative numbers, the home-range estimates (Table 1) indicate clearly that reptiles have smaller home ranges than other diurnal predators and, therefore, will be the most abundant predators in the study area. As a consequence, the absence of reptiles in winter should represent a significant reduction in the predation risk of diurnal activity. However, the energetic differences between endothermic (mammals and birds) and ectothermic (reptiles) predators is great, with placental mammals and birds having field metabolic rates $\sim 17$ times higher than those of similar-sized reptiles (Nagy 1987). As a consequence, endothermic predators active in winter will still represent a major threat to basking $P$. macdonnellensis.

The continued predation threat faced by $P$. macdonnellensis in winter is a likely explanation for the use of basking sites located close to refuge sites. Similar behaviour has been observed in other saxicoline, basking mammals (Mzilikazi et al. 2002; Brown and Downs 2005). Close proximity of refuge and basking sites reduces commuting time when animals are potentially exposed to predators while their locomotor abilities are impaired at low $\mathrm{T}_{\mathrm{b}}$ (Rodriguez-Gironés 2002), and, as with ectothermic reptiles, ensures a greater probability of escape in the event of attempted predation (Cooper 2000). A further advantage is that shuttling between sun-exposed and protected areas can readily occur (Hainsworth 1995), a strategy used by P. macdonnellensis in our study. The physical requirements of refuge and basking sites of $P$. macdonnellensis differ; specifically, refuge sites should provide a buffer against temperature extremes, water loss and predators, whereas basking sites should maximise exposure to early morning or afternoon sun. Therefore, the availability of torpor and basking sites in close juxtaposition must be an important characteristic of home ranges of this species.

We found that basking bouts were longest soon after sunrise and decreased with time since sunrise. This pattern may have resulted from the higher $\mathrm{T}_{\mathrm{a}}$ in the afternoon, thus making thermoregulation cheaper. Alternatively, it may be a response to the potential presence of predatory reptiles, which are sometimes active on warm afternoons in winter after rewarming in the morning.

Several aspects of the basking behaviour of P. macdonnellensis indicate that animals employ a strategy that aims to maximise warming efficiency. First, basking animals typically flattened their bodies against rock surfaces thereby maximising heat gain through conduction from the sun-exposed rock. Second, animals maximised sun-exposure of the dorsal surface. Regardless of the body posture, animals typically orientated the posterior of the body towards the sun while basking. Last, basking animals frequently switched position while basking. This movement included changing the orientation of the body towards the sun and moving more of the body into or out of the sun as required. These and other behaviours of $P$. macdonnellensis have much in common with those used by desert-dwelling ectotherms, including the frequency of basking on sun-exposed rock early in the morning, use of adjacent rock crevices for refuge, adjusting body posture in relation to solar radiation, and increased duration of basking bouts early in the day (Mayhew 1968; Nagy 1973; Carrascal et al. 1992). Further, most P. macdonnellensis commenced diurnal foraging after passive rewarming by basking, as do desert ectotherms (Huey and Pianka 1977; Cooper 2000). Given these behavioural similarities and the behavioural control of thermoregulation in many reptiles, further understanding of the degree of behavioural regulation of temperature by endotherms during basking needs further investigation.

Our study is an example of the use of new technology to provide insights into animal behaviour. In contrast to other basking mammals (e.g. Brown and Downs 2005), the small size of this species meant that we could not have located basking or foraging animals without using radio-telemetry. However, external transmitters remain attached to the study species for very short periods (Gilfillan 2001b; Pavey et al. 2003); therefore, implanted transmitters were needed. Although implant transmitters were developed specifically to collect thermal data they worked very well for our purposes. Therefore, wider use of this method should be considered, especially for studies in which long-term data are required.

\section{Acknowledgements}

We thank Nicola Goodship for field assistance throughout the study. Michael Barritt, Silke Beckedorf, Karen May, and Parks and Wildlife Service of the Northern Territory staff based at Ormsiton provided assistance and logistic support during the study. We thank Gavin Bedford and Greg Fyfe for expert advice on predatory reptiles in the study area. We are grateful to R. Mark Brigham, Ed Heske and an anonymous reviewer for comments on the manuscript. Permits were provided by the Animal Ethics Committee of the University of New England and the Parks and Wildlife Service of the Northern Territory. The research was supported by grants from the Australian Research Council and the Faculty of Sciences, The University of New England.

\section{References}

Bedford, G. S., and Christian, K. A. (1998). Standard metabolic rate and preferred body temperatures in some Australian pythons. Australian Journal of Zoology 46, 317-328. doi: 10.1071/ZO98019

Brown, K. J., and Downs, C. T. (2005). Seasonal behavioural patterns of freeliving rock hyrax (Procavia capensis). Journal of Zoology 265, 311-326. doi: $10.1017 / \mathrm{S} 0952836905006412$

Burton, A. M., and Olsen, P. (2000). Niche partitioning by two sympatric goshawks in the Australian Wet Tropics: ranging behaviour. Ети 100, 216-226. doi: 10.1071/MU9915

Burwell, C. J., Geiser, F., Barritt, M., May, K., and Pavey, C. R. (2005). Additional records of prey of the fat-tailed false antechinus Pseudantechinus macdonnellensis from central Australia. Australian Mammalogy 27, 227-229.

Carrascal, L. M., López, P., Martín, J., and Salvador, A. (1992). Basking and antipredator behaviour in a high altitude lizard: implications of heatexchange rate. Ethology 92, 143-154.

Cooper, W. E. Jr (2000). Effect of temperature on escape behaviour by an ectothermic vertebrate, the keeled earless lizard (Holbrookia propinqua). Behaviour 137, 1299-1315. doi: 10.1163/156853900501935 
Edwards, G. P., de Preu, N., Shakeshaft, B. J., Crealy, I. V., and Paltridge, R. M. (2001). Home range and movements of male feral cats (Felis catus) in a semiarid woodland environment in central Australia. Austral Ecology 26, 93-101. doi: 10.1046/j.1442-9993.2001.01091.x

Eldridge, S. R., Shakeshaft, B. J., and Nano, T. J. (2002). The impact of wild dog control on cattle, native and introduced herbivores and introduced predators in central Australia. Final report to Bureau of Rural Sciences. Northern Territory Parks and Wildlife Commission, Alice Springs, Northern Territory, Australia.

Geiser, F., and Pavey, C. R. (2007). Basking and torpor in a rock-dwelling desert marsupial: survival strategies in a resource-poor environment. Journal of Comparative Physiology. B, Biochemical, Systemic, and Environmental Physiology 177, 885-892. doi: 10.1007/s00360-007-0186-z

Geiser, F., Goodship, N., and Pavey, C. R. (2002). Was basking important in the evolution of mammalian endothermy? Naturwissenschaften 89, 412-414. doi: 10.1007/s00114-002-0349-4

Geiser,F., Drury, R. L., Körtner, G., Turbill,C.,Pavey,C.R., and Brigham, R.M. (2004). Passive rewarming from torpor in mammals and birds: energetic, ecological and evolutionary implications. In 'Life in the Cold: Evolution, Mechanisms, Adaptation, and Application'. (Eds B. M. Barnes and H. V. Carey.) pp. 51-62. Biological Papers of the University of Alaska No. 27. (Fairbanks, AK.)

Geiser, F., Christian, N., Cooper, C. E., Körtner, G., McAllan, B. M., Pavey, C. R., Turner, J. M., Warnecke, L., Willis, C. K. R., and Brigham, R. M. (2008). Torpor in marsupials: recent advances. In 'Hypometabolism in Animals: Torpor, Hibernation and Cryobiology. 13th International Hibernation Symposium'. (Eds B. G. Lovegrove and A. E. McKechnie.) pp. 297-306. (University of KwaZulu-Natal: Pietermaritzburg.)

Gilfillan, S. (1995). The ecology of a central Australian population of Pseudantechinus macdonnellensis (Marsupialia: Dasyuridae). Ph.D. Thesis, La Trobe University, Melbourne.

Gilfillan, S. (2001a). An ecological study of a population of Pseudantechinus macdonnellensis (Marsupialia: Dasyuridae) in central Australia. I. Invertebrate food supply, diet and reproductive strategy. Wildlife Research 28, 469-480. doi: 10.1071/WR99062

Gilfillan, S. (2001b). An ecological study of a population of Pseudantechinus macdonnellensis (Marsupialia: Dasyuridae) in central Australia. II. Population dynamics and movements. Wildlife Research 28, 481-492. doi: 10.1071/WR99063

Hainsworth, F. R. (1995). Optimal body temperatures with shuttling - desert antelope ground-squirrels. Animal Behaviour 49, 107-116. doi: 10.1016/ 0003-3472(95)80158-8

Higgins, P. (1999). 'Handbook of Australian, New Zealand and Antarctic birds. Volume 4: Parrots to Dollarbird.' (Oxford University Press: Melbourne.)

Huey, R. B., and Pianka, E. B. (1977). Seasonal variation in thermoregulatory behavior and body temperature of diurnal Kalahari lizards. Ecology $\mathbf{5 8}$, 1066-1075. doi: 10.2307/1936926

Kenagy, G. J., Nespolo, R. F., Vásquez, R. A., and Bozinovic, F. (2002). Daily and seasonal limits of time and temperature to activity of degus. Revista Chilena de Historia Natural 75, 567-581.

King, D., Green, B., and Butler, H. (1989). The activity pattern, temperature regulation and diet of Varanus giganteus on Barrow Island, Western Australia. Australian Wildlife Research 16, 41-47. doi: 10.1071/ WR9890041
Kramer, M., and Schmidhammer, J. (1992). The chi-squared statistic in ethology: use and misuse. Animal Behaviour 44, 833-841. doi: 10.1016/ S0003-3472(05)80579-2

Lima, S. L., and Bednekoff, P. (1999). Temporal variation in danger drives antipredator behavior: the predation risk allocation hypothesis. American Naturalist 153, 649-659. doi: 10.1086/303202

Lima, S. L., and Dill, L. M. (1990). Behavioral decisions made under the risk of predation: a review and prospectus. Canadian Journal of Zoology 68 , 619-640.

Marchant, S., and Higgins, P. (1993). 'Handbook of Australian, New Zealand and Antarctic birds. Volume 2: Raptors to Lapwings.' (Oxford University Press: Melbourne.)

Mayhew, W. W. (1968). Biology of desert amphibians and reptiles. In 'Desert Biology. Vol. 1'. (Ed. G. W. Brown Jr.) pp. 195-356. (Academic Press: New York.)

Mzilikazi, N., and Lovegrove, B. G. (2005). Daily torpor during the active phase in free-ranging rock elephant shrews (Elephantulus myurus). Journal of Zoology 267, 103-111. doi: 10.1017/S0952836905007314

Mzilikazi, N., Lovegrove, B. G., and Ribble, D. O. (2002). Exogenous passive heating during torpor arousal in free-ranging rock elephant shrews, Elephantulus myurus. Oecologia 133, 307-314. doi: 10.1007/s00442002-1052-z

Nagy, K. (1973). Behavior, diet and reproduction in a desert lizard Sauromalus obesus. Copeia 1973, 93-102. doi: 10.2307/1442363

Nagy, K. A. (1987). Field metabolic rate and food requirement scaling in mammals and birds. Ecological Monographs 57, 111-128. doi: 10.2307/ 1942620

Pavey, C. R., Goodship, N., and Geiser, F. (2003). Home range and spatial organization of the rock-dwelling carnivorous marsupial, Pseudantechinus macdonnellensis. Wildlife Research 30, 135-142. doi: 10.1071/WR03005

Rodriguez-Gironés, M. A. (2002). Predicting body temperature of endotherms during shuttling. Journal of Thermal Biology 27, 393-403. doi: 10.1016/S0306-4565(02)00008-6

Schmid, J. (2000). Daily torpor in the gray mouse lemur (Microcebus murinus) in Madagascar: energetic consequences and biological significance. Oecologia 123, 175-183. doi: 10.1007/s004420051003

Shine, R., and Fitzgerald, M. (1996). Large snakes in a mosaic rural landscape: the ecology of carpet pythons Morelia spilota (Serpentes: Pythonidae) in coastal eastern Australia. Biological Conservation 76, 113-122. doi: 10.1016/0006-3207(95)00108-5

Thompson, G. G., de Boer, M., and Pianka, E. R. (1999). Activity areas and daily movements of an arboreal monitor lizard, Varanus tristis (Squamata: Varanidae) during the breeding season. Australian Journal of Ecology 24, 117-122. doi: 10.1046/j.1442-9993.1999.241952.x

Whitaker, P. B., and Shine, R. (2003). A radiotelemetric study of movements and shelter-site selection by free-ranging brownsnakes (Pseudonaja textilis, Elapidae). Herpetological Monograph 17, 130-144. doi: 10.1655/ 0733-1347(2003)017[0130:ARSOMA]2.0.CO;2

White, G. C., and Garrott, R. A. (1990). 'Analysis of Wildlife Radio-tracking Data.' (Academic Press: London.)

Manuscript received 21 March 2008, accepted 13 August 2008 